\section{Corneal topography and Schirmer testing in eyes with the Hudson-Stahli line}

SK Rao, VS Ananth and P Padmanabhan

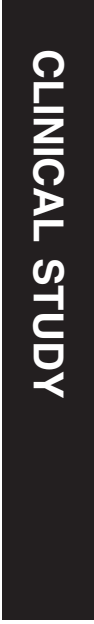

\begin{abstract}
Purpose To evaluate corneal topographic features and tear secretion in eyes with the Hudson-Stahli line.

Methods Keratometry, computerized videokeratography and Schirmer testing were performed in 50 cases with bilateral Hudson-Stahli line, and 55 controls without the Hudson-Stahli line. Similar tests were performed in 21 subjects with unilateral Hudson-Stahli line.

Results Corneal topographic features and keratometry in the horizontal meridian were similar in cases and controls, and in fellow eyes of subjects with unilateral HudsonStahli line. Keratometry in the vertical

formed by the deposition of iron in the epithelium of an otherwise normal cornea and is considered a physiological change, seen more frequently with increasing age. ${ }^{2}$ The source of iron and etiopathogenesis of the Hudson-Stahli line remain controversial, although tear film pooling is thought to be important. ${ }^{3}$ Recent studies have reported the formation of corneal pigment lines after corneal refractive surgery, suggesting that alterations in corneal surface contour may play an important role in the formation of these lines. ${ }^{4-6}$ We performed corneal topographic examination and Schirmer testing in patients with the Hudson-Stahli line to assess the corneal surface contour and tear secretion in their eyes.
\end{abstract} meridian in cases $(43.01 \pm 2.01)$ was significantly lesser than in controls $(43.94 \pm$ 1.77) $(P=0.01)$. This value was not different in fellow eyes of patients with unilateral Hudson-Stahli line. Schirmer testing revealed significantly greater tear secretion in cases $(16.72 \pm 4.99 \mathrm{~mm})$ compared to controls $(12.57 \pm 3.62 \mathrm{~mm})(P<0.01)$. In subjects with unilateral Hudson-Stahli line, mean Schirmer values in the eye with the line $(17.52 \pm 6.86 \mathrm{~mm})$ were significantly greater than in eyes without $(13.67 \pm 4.64 \mathrm{~mm})(P=$ 0.04).

Conclusion Formation of the Hudson-Stahli line may be dependent on the presence of normal tear secretion in the eye. Eye (2002) 16, 267-270. DOI: 10.1038/ sj/eye/6700028

Keywords: corneal topography; Hudson-Stahli line; tear secretion

The Hudson-Stahli line, described independently by Hudson and Stahli, is a fine, horizontal, brown line in the corneal epithelium along the line of lid closure. ${ }^{1}$ It is

\section{Subjects and methods}

We performed the study in two parts. In part I, we enrolled 50 patients aged 40 years or more, in whom slit-lamp biomicroscopy revealed the presence of a Hudson-Stahli line in both eyes. Exclusion criteria included corneal disease, previous ocular surgery, longterm use of ocular medication, and contact lens use. We also enrolled 55 age-matched controls, who did not have the Hudson-Stahli line in either eye. All patients signed an informed consent.

After routine ophthalmic evaluation, cases and controls underwent keratometry (ShinNippon, Tokyo, Japan), corneal topography (TMS-2 videokeratoscope, Computed Anatomy, New York), and Schirmer testing. Data from the right eye of cases and controls were used for analysis. The topographic map (absolute scale) was classified as round, oval, symmetric bowtie, asymmetric bowtie or irregular. ${ }^{7}$ The surface regularity index (SRI) and the surface asymmetry index (SAI), from the topographic map, were noted. Schirmer testing was performed in a dimly lit room
Sankara Nethralaya

Medical Research

Foundation

Chennai, India

Correspondence: SK Rao

Cornea Service

Medical Research

Foundation

18 College Road

Chennai 600006

Tamil Nadu, India

Tel: 8271616, 8271036 8261268

Fax: 910448254180

910448210117

E-mail:mrf@sankara

nethralaya.org

mrf@md3.vsnl.net.in 
Table 1 Test results in cases and controls (part I of the study)

\begin{tabular}{lcc}
\hline & Cases & Controls \\
\hline Keratometry (mean \pm SD) & & $43.94 \pm 1.78 \mathrm{D}$ \\
$\quad$ Vertical meridian* & $43.01 \pm 2.01 \mathrm{D}$ & $44.50 \pm 1.83 \mathrm{D}$ \\
$\quad$ Horizontal meridian & $43.75 \pm 5.35 \mathrm{D}$ & $0.80 \pm 0.39$ \\
Corneal videokeratography & & $0.45 \pm 0.35$ \\
$\quad$ Surface regularity index** (mean \pm SD) & $0.69 \pm 0.22$ & $12.57 \pm 3.62 \mathrm{~mm}$ \\
$\quad$ Surface asymmetry index (mean \pm SD) & $16.72 \pm 4.99 \mathrm{~mm}$ & \\
Schirmer test** (mean \pm SD) &
\end{tabular}

${ }^{*} P=0.01 ;{ }^{* *} P=0.054 ;{ }^{* *} P<0.01$.

using standard 35-mm strips, without topical anesthesia. The strip was placed in the lower conjunctival cul-de-sac at the junction of the middle and outer one-third of the lower lid. The extent of wetting of the strip was measured at the end of $5 \mathrm{~min}$. In part II of the study, 21 patients with unilateral Hudson-Stahli line were studied. Exclusion criteria and study methodology were similar to that described for part I of the study.

The $t$-test was used to compare the mean Schirmer values, of cases and controls in part I of the study, and in the right and left eyes of subjects, in part II of the study.

\section{Results}

\section{Part I of the study}

The average age of the 50 cases ( 22 males, 28 females) was $57.9 \pm 9.7$ years (range $40-83$ years). This was not different from the mean age of the 55 controls ( 32 males, 23 females), $59.12 \pm 11.52$ years (range $42-85$ years). The results of keratometry, corneal topography and Schirmer testing in cases and controls are described in Table 1. Mean horizontal keratometry and SAI values were similar in cases and controls. Vertical keratometry in cases $(43.02 \pm 2.01)$ was less than that in controls $(43.94 \pm 1.77)(P=0.01)$. The surface regularity index in controls was greater, indicating a more irregular surface, with the difference approaching statistical significance $(P=0.054)$. No distinct corneal topographic pattern was observed in the cases. The mean Schirmer value in cases $(16.72 \pm 4.99 \mathrm{~mm}$, range 10-30 mm) was significantly greater than that in controls $(12.57 \pm 3.62 \mathrm{~mm}$, range $5-25 \mathrm{~mm})(P<0.01)$.

\section{Part II of the study}

The average age of the 21 subjects (eight males, 13 females) was $61.8 \pm 10.3$ years (range $45-90$ years). The results of keratometry, corneal topography, and Schirmer testing in the right and left eye of the study group are described in Table 2. Mean horizontal and vertical keratometry, SRI and SAI values were similar in fellow eyes of patients. No distinct corneal topographic pattern was observed in eyes with the Hudson-Stahli line. The mean Schirmer value in eyes with the Hudson-Stahli line $(17.52 \pm 6.86 \mathrm{~mm}$, range 5-30 $\mathrm{mm}$ ) was significantly greater than that in eyes without $(13.67 \pm 4.64 \mathrm{~mm}$, range $5-22 \mathrm{~mm})(P=0.04)$.

\section{Comment}

Corneal epithelial pigment lines, similar to the Hudson-Stahli line, have also been described in other corneal conditions-keratoconus (Fleischer ring), filtering bleb (Ferry line); pterygium (Stocker line), in association with corneal scars, and after penetrating keratoplasty. ${ }^{3}$ Recently, such lines have been described after a variety of corneal refractive procedures. ${ }^{4-6}$

Table 2 Test results in fellow eyes of subjects with unilateral Hudson-Stahli line (part II of the study)

\begin{tabular}{lcc}
\hline & Eye with Hudson-Stahli line & Eye without Hudson-Stahli line \\
\hline Keratometry (mean $\pm \mathrm{SD})$ & & \\
$\quad$ Vertical meridian & $44.84 \pm 1.27 \mathrm{D}$ & $44.66 \pm 1.43 \mathrm{D}$ \\
$\quad$ Horizontal meridian & $44.91 \pm 1.29 \mathrm{D}$ & $44.95 \pm 1.29 \mathrm{D}$ \\
Corneal videokeratography & $0.88 \pm 0.32$ \\
$\quad$ Surface regularity index (mean \pm SD) & $0.47 \pm 0.23$ \\
$\quad$ Surface asymmetry index (mean \pm SD) & $17.52 \pm 6.86 \mathrm{~mm}$ \\
Schirmer test* (mean \pm SD) & $0.78 \pm 0.28$ \\
\hline
\end{tabular}

${ }^{*} P=0.04$. 
Although it has been suggested that all of these iron lines are identical histologically and histochemically, ${ }^{8,9}$ the exact source and mechanism of iron deposition in the corneal epithelium are yet to be determined. The reason for the variation in corneal location of these lines is also not clear.

In 1964, Gass ${ }^{2}$ suggested that iron from various sources, including tears, is deposited within the basal epithelial cells of the cornea causing pigment lines. This report has produced the tear pool hypothesis, according to which altered corneal topography results in localized tear pooling. The sequestered tear film iron accumulates in the basal epithelial cells that lie beneath the pooled tear layer, producing localized iron lines in the cornea. The Hudson-Stahli line is therefore, thought to result from eyelid-blink associated tear pooling. ${ }^{3}$

In 1987, Rose and Lavin ${ }^{1}$ proposed the basal cell migration theory, in which they suggested that iron deposition might be modulated by surface epithelial cell turnover. They hypothesized that surface epithelial cell attrition is greatest in the lower two-thirds of the cornea, with increased basal cell mitoses and a decreased rate of basal cell migration. The population of rapidly dividing, nonmigrating basal cells would therefore, become relatively mature. Iron accumulation in these cells, with time, would result in the characteristic pattern of iron deposition.

More recently, Assil et $a l^{5}$ have suggested a modification of the existing hypotheses for corneal epithelial pigment formation, based on their study of these lines in eyes with corneal intrastromal ring implantation. They proposed that tear desiccation in certain zones results in an increased concentration of soluble iron. When this tear breakup occurs in areas with diminished cell turnover rates, iron accumulates in the basal epithelial cells of the cornea. They hypothesized that the junction of the upper two-thirds and lower one third of the cornea is prone to tear film instability, and represents a zone of senescent corneal epithelial cells. They thus, proposed that these two factors are responsible for the formation of the Hudson-Stahli line.

Both factors described in the above hypothesis are present in humans, from birth. Although the HudsonStahli line has been described in children, ${ }^{2}$ it mostly occurs after the fifth decade. ${ }^{10}$ The reason for this delayed occurrence of the Hudson-Stahli line is not clear, especially since pigment lines form as early as 612 months after surgical alteration of corneal topography. ${ }^{4-6}$ Abrupt alterations in the normal prolate corneal shape therefore, seem to hasten the deposition of iron in basal epithelial cells in certain areas of the cornea.
Since the corneal epithelium is constantly renewed every 7-10 days, ${ }^{11}$ the concept of the senescent cell seems unlikely. It has also been shown that pigments are present in the basal epithelium throughout the corneal surface, ${ }^{2,12}$ implying that they are a normal component of this layer. The existing hypotheses also do not explain the disappearance of corneal pigment within 3 months after removal of the intrastromal corneal ring. ${ }^{5}$

Finally, since tear film dessication and cell senescence in the interpalpebral cornea are expected in all eyes, the variable occurrence of the Hudson-Stahli line is hard to explain. The line is seen in $29-90 \%$ of persons aged 60 years or more. ${ }^{2,10,13}$ The unilateral occurrence of the Hudson-Stahli line, in $57 \%$ of 287 subjects in a recent study, ${ }^{14}$ also indicates that there are as yet unexplained factors that influence formation of corneal pigment lines.

Our study did not detect a specific corneal topographic pattern in eyes with the Hudson-Stahli line, compared to controls. We are not clear about the significance of increased vertical keratometry values in controls in part I of the study. There was no significant difference in keratometry values in fellow eyes of patients with unilateral Hudson-Stahli line. There was however, significantly greater tear secretion in eyes with the Hudson-Stahli line, as measured by the Schirmer test. We chose not to use topical anesthesia for the test, as studies have shown that an anesthetized ocular surface reduces tear flow dramatically, ${ }^{15}$ resulting in an unphysiological situation. A reduction in Schirmer test values with increasing age has been documented previously. ${ }^{15}$ A study of 72 subjects aged 10 years or older, revealed a mean Schirmer value of $16.61 \pm 10.72 .{ }^{16}$ Although the values declined significantly with age, a sharp decline was noted after the sixth decade. Studies on the epidemiology of the Hudson-Stahli line, ${ }^{1,13}$ have indicated that there is a small decline in the incidence of the line in the eighth and ninth decades. This may be due to the steep decline in tear secretion in the elderly and corroborates our finding of reduced tear secretion in eyes without the Hudson-Stahli line.

The surface regularity index, was greater in eyes of controls in part I of the study, although the difference did not attain statistical significance $(P=0.054)$.

Reduced tear secretion is one cause of increased corneal surface irregularity and corroborates the results of Schirmer testing indicating reduced tear secretion in these eyes. However, the SRI values were not different in fellow eyes of patients, in part II of the study.

In conclusion, while the exact etiopathogenesis of the Hudson-Stahli line is still unclear, our study indicates 
that a normal tear film may be essential for the formation of these lines.

\section{References}

1 Rose GE, Lavin MJ. The Hudson-Stahli line III Observations on morphology, a critical review of etiology and a unified theory for the formation of iron line of the corneal epithelium. Eye 1987; 1: 475-479.

2 Gass JD. The iron lines of the superficial cornea: HudsonStahli line, Stocker's line and Fleischer's ring. Arch Ophthalmol 1964; 71: 348-358.

3 Mannis MJ. Iron deposition in the corneal graft-another corneal iron line. Arch Ophthalmol 1983; 101: 1858-1861.

4 Steinberg EB, Wilson LA, Waring GO III, Lynn MJ, Coles WH. Stellate lines in the corneal epithelium after radial keratotomy. Am I Ophthalmol 1984; 98: 416-421.

5 Assil KA, Quantock AJ, Barrett AM, Schanzlin DJ. Corneal iron lines associated with the intrastromal corneal ring. Am J Ophthalmol 1993; 116: 350-356.

6 Ozdamar A, Aras C, Sener B, Karacorlu M. Corneal iron ring after hyperopic laser-assisted in situ keratomileusis. Cornea 1999; 18: 243-245.

7 Bogan SJ, Waring GO III, Ibrahim O, Drews C, Curtis L.
Classification of normal corneal topography based on computer-assisted videokeratography. Arch Ophthalmol 1990; 108: 945-949.

8 Barraquer-Somers E, Chan CC, Green RW. Corneal epithelial iron deposition. Ophthalmology 1983; 90: 729734.

9 Koenig SB, McDonald MB, Yamaguchi T, Friedlander M, Ishii Y. Corneal iron lines after refractive keratoplasty. Arch Ophthalmol 1983; 101: 1862-1865.

10 Rose GE, Lavin MJ. The Hudson-Stahli line I: an epidemiological study. Eye 1987; 1: 466-470.

11 Hanna C, O'Brien JE. Cell production and migration in the epithelial layer of the cornea. Arch Ophthalmol 1960 64: $536-539$

12 Iwamoto T, De Voe AG. Electron microscopical study of the Fleischer ring. Arch Ophthalmol 1976; 94: 1979-1984.

13 Norn MS. Hudson-Stahli's line of cornea. I. Incidence and morphology. Acta Ophthalmol 1968; 46: 106-118.

14 Norn M. Hudson-Stahli's iron line in the cornea. Occurrence in 1968 and 1988. Acta Ophthalmol (Copenh) 1990; 68: 339-340.

15 Jordan A, Baum J. Basic tear flow: does it exist? Ophthalmology 1980; 87: 920-930.

16 Mathers WD, Lane JA, Zimmerman WB. Tear film changes associated with normal aging. Cornea 1996; 15: 229-234. 